\title{
Comparative Study of Anion Exchange Resins Purolite NRW-6000 and Duolite A-143 by Application Isotopic Technique
}

\author{
P. U. Singare \\ Department of Chemistry, Bhavan's College, Munshi Nagar, Andheri (West), \\ Mumbai 400 058, India \\ Tel No. + 9122 26256451/ 52 (Office), Fax No. + 912226256453 (Office)
}

E-mail address: pravinsingare@gmail.com

\begin{abstract}
Isotopic tracer technique using ${ }^{131} \mathrm{I}$ and ${ }^{82} \mathrm{Br}$ was used to characterize Purolite NRW-6000 and Duolite A-143 anion exchange resins. The characterization study was done by carrying out iodide and bromide ion-isotopic exchange reactions taking place between the resin surface and the external labeled ionic solution. For the two resins it was observed that under identical experimental conditions, the values of specific reaction rate $\left(\mathrm{min}^{-1}\right)$, amount of ion exchanged $(\mathrm{mmol})$ and initial rate of ion exchange $(\mathrm{mmol} / \mathrm{min})$ were calculated to be lower for bromide ion-isotopic exchange reaction than that for iodide ion-isotopic exchange reaction. Also during both the ion-isotopic exchange reactions, under identical experimental conditions for the two resins, the values of specific reaction rate increases with increase in ionic concentration and was observed to decrease with rise in temperature. For a constant temperature of $35.0^{\circ} \mathrm{C}$, as the concentration of labeled bromide ion solution increases from $0.001 \mathrm{~mol} / \mathrm{L}$ to $0.004 \mathrm{~mol} / \mathrm{L}$, the percentage of bromide ions exchanged increases from $67.80 \%$ to $72.76 \%$ using Purolite NRW-6000 resin and from $42.54 \%$ to $50.45 \%$ using Duolite A-143 resin. However when the temperature was raised from $30.0{ }^{\circ} \mathrm{C}$ to $45.0^{\circ} \mathrm{C}$ by keeping the concentration of labeled bromide ion solution constant at $0.002 \mathrm{~mol} / \mathrm{L}$, the percentage of bromide ions exchanged decreases from $70.68 \%$ to $67.32 \%$ using Purolite NRW-6000 resin and from $47.50 \%$ to $42.25 \%$ using Duolite A-143 resin. From the results it appears that Purolite NRW-6000 resins show superior performance over Duolite A-143 resins under identical experimental conditions. It is expected that the present isotopic tracer technique can be applied further as an efficient nondestructive technique in characterization of various ion exchange resins so as to bring about their efficient industrial applications.
\end{abstract}

Keywords: isotopic technique; tracer isotopes; ${ }^{131} \mathrm{I} ;{ }^{82} \mathrm{Br}$; resin characterization; industrial grade resins; Purolite NRW-6000; Duolite A-143

\section{INTRODUCTION}

A large number of organic materials exhibit ion exchange properties; these include polysaccharides (such as cellulose, algic acid, straw and peat), proteins (such as casein, keratin and collagen) and carbonaceous materials (such as charcoals, lignites and coals). Of these, only charcoals, coal, lignite and peat are used commercially. Although they exhibit a very low ion exchange capacity compared with synthetics, they are widely available at a very low cost. 
They are normally used as general sorbents, with their ion exchange properties being a secondary consideration. Commercially available materials are often treated or stabilized with other additives to improve their uniformity or stability. Some materials, such as charcoals, can be doped with chemicals to improve their capacity or selectivity. Ion exchange materials can be categorized according to their suitability for different applications. A wide range of materials is available for the ion exchange treatment of radioactive liquids [1,2]. These materials are available in a variety of forms, have widely differing chemical and physical properties and can be naturally occurring or synthetic. Nuclear grade organic ion exchange resins are normally used when liquids from primary circuits or fuel pools are purified [3].

The type of material to be used is selected based on its ability to remove impurities and undesirable ions and to control $\mathrm{pH}$. Nuclear grade ion exchangers are similar to commercial grade resins but have a tighter specification for particle size and composition.

These resins are often used for a number of treatment cycles by eluting the absorbed radioisotopes with suitable solutions and then restoring the ion exchanger to its original ionic form before its reuse [3]. Efforts to develop new organic ion exchangers for their specific applications in nuclear industries are continuing and various aspects of ion exchange technologies have been continuously studied to improve the efficiency and economy of their application in various technological applications $[4,5]$.

However, since the selection of the appropriate ion-exchange material depends on the needs of the system, it is expected that the data obtained from the actual experimental trials will prove to be more helpful. Hence there is a need to evaluate systematically the performance of such organic ion exchange resins under various operational conditions.

Therefore in the present investigation, it is proposed to access the performance of Purolite NRW-6000 (nuclear grade) and Duolite A-143 (non nuclear grade) ion exchange resins under different experimental conditions like temperature and concentration of ionic species present in the external exchanging medium.

\section{EXPERIMENTAL}

\section{1. Conditioning of ion exchange resins}

Purolite NRW-6000 is a nuclear grade Type I porous gel strong base anion exchange resin in hydroxide form (supplied by Purolite International India Private Limited, Pune, India) while Duolite A-143 is a strongly basic anion exchange resin in chloride form (supplied by Auchtel Products Ltd., Mumbai, India). Details regarding the properties of the resins used are given in Table 1.

These resins were converted separately in to iodide / bromide form by treatment with 10 $\% \mathrm{KI} / \mathrm{KBr}$ solution in a conditioning column which is adjusted at the flow rate as $1 \mathrm{~mL} /$ min. The resins were then washed with double distilled water, until the washings were free from iodide/bromide ions as tested by $\mathrm{AgNO}_{3}$ solution.

Thes resins in bromide and iodide form were then dried separately over $\mathrm{P}_{2} \mathrm{O}_{5}$ in desiccators at room temperature. 
Table 1. Properties of ion exchange resins.

\begin{tabular}{|c|c|c|c|c|c|c|c|}
\hline $\begin{array}{c}\text { Ion } \\
\text { exchange } \\
\text { resin }\end{array}$ & Matrix & $\begin{array}{c}\text { Functional } \\
\text { Group }\end{array}$ & $\begin{array}{c}\text { Mean } \\
\text { Particle } \\
\text { Size } \\
(\mathrm{mm})\end{array}$ & $\begin{array}{c}\text { Moisture } \\
\text { content } \\
(\%)\end{array}$ & $\begin{array}{c}\text { Operating } \\
\mathrm{pH}\end{array}$ & $\begin{array}{c}\text { Maximum } \\
\text { operating } \\
\text { temperature } \\
\left({ }^{\circ} \mathrm{C}\right)\end{array}$ & $\begin{array}{c}\text { Total } \\
\text { exchange } \\
\text { capacity } \\
(\mathrm{mEq} . / \mathrm{mL})\end{array}$ \\
\hline $\begin{array}{c}\text { Purolite } \\
\text { NRW-6000 }\end{array}$ & $\begin{array}{c}\text { polystyrene } \\
\text { crosslinked } \\
\text { with divinyl } \\
\text { benzene }\end{array}$ & $-\mathrm{N}^{+} \mathrm{R}_{3}$ & 0.63 & 60 & $0-14$ & 60 & 1.1 \\
\hline Duolite & $\begin{array}{c}\text { Crosslinked } \\
\text { polystyrene }\end{array}$ & $-\mathrm{N}^{+} \mathrm{R}_{3}$ & 0.75 & 65 & $0-14$ & 100 & 1.00 \\
\hline
\end{tabular}

\section{2. Radioactive Tracer Isotopes}

The radioisotope ${ }^{131} \mathrm{I}$ and ${ }^{82} \mathrm{Br}$ used in the present experimental work was obtained from Board of Radiation and Isotope Technology (BRIT), Mumbai, India. Details regarding the isotopes used in the present experimental work are given in Table 2.

Table 2. Properties of ${ }^{131} \mathrm{I}$ and ${ }^{82} \mathrm{Br}$ tracer isotopes [6].

\begin{tabular}{|c|c|c|c|c|c|}
\hline Isotopes & Half-life & $\begin{array}{c}\text { Radioactivity } \\
/ \mathrm{mCi}\end{array}$ & $\begin{array}{c}\gamma \text { - energy } \\
/ \mathrm{MeV}\end{array}$ & $\begin{array}{c}\text { Chemical } \\
\text { form }\end{array}$ & $\begin{array}{c}\text { Physical } \\
\text { form }\end{array}$ \\
\hline${ }^{131} \mathrm{I}$ & $8.04 \mathrm{~d}$ & 5 & 0.36 & Iodide* $^{*}$ & Aqueous \\
\hline${ }^{82} \mathrm{Br}$ & $36 \mathrm{~h}$ & 5 & 0.55 & Bromide** $^{* *}$ & Aqueous \\
\hline
\end{tabular}

* Sodium iodide in dilute sodium sulphite.

** Ammonium bromide in dilute ammonium hydroxide.

\section{3. Study on kinetics of iodide ion-isotopic exchange reaction}

In a stoppered bottle $250 \mathrm{~mL}(V)$ of $0.001 \mathrm{~mol} / \mathrm{L}$ iodide ion solution was labeled with diluted ${ }^{131}$ I radioactive solution using a micro syringe, such that $1.0 \mathrm{~mL}$ of labeled solution has a radioactivity of around $15,000 \mathrm{cpm}$ (counts per minute) when measured with $\gamma$-ray spectrometer having NaI (Tl) scintillation detector. Since only about 50-100 $\mu \mathrm{L}$ of the radioactive iodide ion solution was required for labeling the solution, its concentration will remain unchanged, which was further confirmed by potentiometer titration against $\mathrm{AgNO}_{3}$ solution. The above labeled solution of known initial activity $\left(A_{i}\right)$ was kept in a thermostat adjusted to $30.0{ }^{\circ} \mathrm{C}$. The swelled and conditioned dry ion exchange resins in iodide form weighing exactly $1.000 \mathrm{~g}(\mathrm{~m})$ were transferred quickly into this labeled solution which was vigorously stirred by using mechanical stirrer and the activity in cpm of $1.0 \mathrm{~mL}$ of solution was measured. The solution was transferred back to the same bottle containing labeled solution after measuring activity. The iodide ion-isotopic exchange reaction can be represented as: 


$$
\mathrm{R}-\mathrm{I}+\mathrm{I}^{*^{-}}{ }_{(\text {aq. }} \rightleftharpoons \mathrm{R}-\mathrm{I}^{*}+\mathrm{I}_{(\text {(aq.) }}^{-}
$$

here R-I represents ion exchange resin in iodide form; $\mathrm{I}^{*^{-}}$(aq.) represents aqueous iodide ion solution labeled with ${ }^{131}$ I radiotracer isotope. The activity of solution was measured at a fixed interval of every $2.0 \mathrm{~min}$. The final activity $\left(A_{f}\right)$ of the solution was also measured after $3 \mathrm{~h}$ which was sufficient time to attain the equilibrium [7-11]. The activity measured at various time intervals was corrected for background counts.

Similar experiments were carried out by equilibrating separately $1.000 \mathrm{~g}$ of ion exchange resin in iodide form with labeled iodide ion solution of four different concentrations ranging up to $0.004 \mathrm{~mol} / \mathrm{L}$ at a constant temperature of $30.0^{\circ} \mathrm{C}$. The same experimental sets were repeated for higher temperatures up to $45.0{ }^{\circ} \mathrm{C}$.

\section{4. Study on kinetics of bromide ion-isotopic exchange reaction}

The experiment was also performed to study the kinetics of bromide ion- isotopic exchange reaction by equilibrating $1.000 \mathrm{~g}$ of ion exchange resin in bromide form with labeled bromide ion solution in the same concentration and temperature range as above. The labeling of bromide ion solution was done by using ${ }^{82} \mathrm{Br}$ as a radioactive tracer isotope for which the same procedure as explained above was followed. The bromide ion-isotopic exchange reaction can be represented as:

$$
\mathrm{R}-\mathrm{Br}+\mathrm{Br}^{*-}{ }_{(\text {aq. })} \rightleftharpoons \mathrm{R}-\mathrm{Br}^{*}+\mathrm{Br}^{-}{ }_{\text {(aq.) }}
$$

here $\mathrm{R}-\mathrm{Br}$ represents ion exchange resin in bromide form; $\mathrm{Br}^{*-}{ }_{(\text {aq.) }}$ represents aqueous bromide ion solution labeled with ${ }^{82} \mathrm{Br}$ radiotracer isotope.

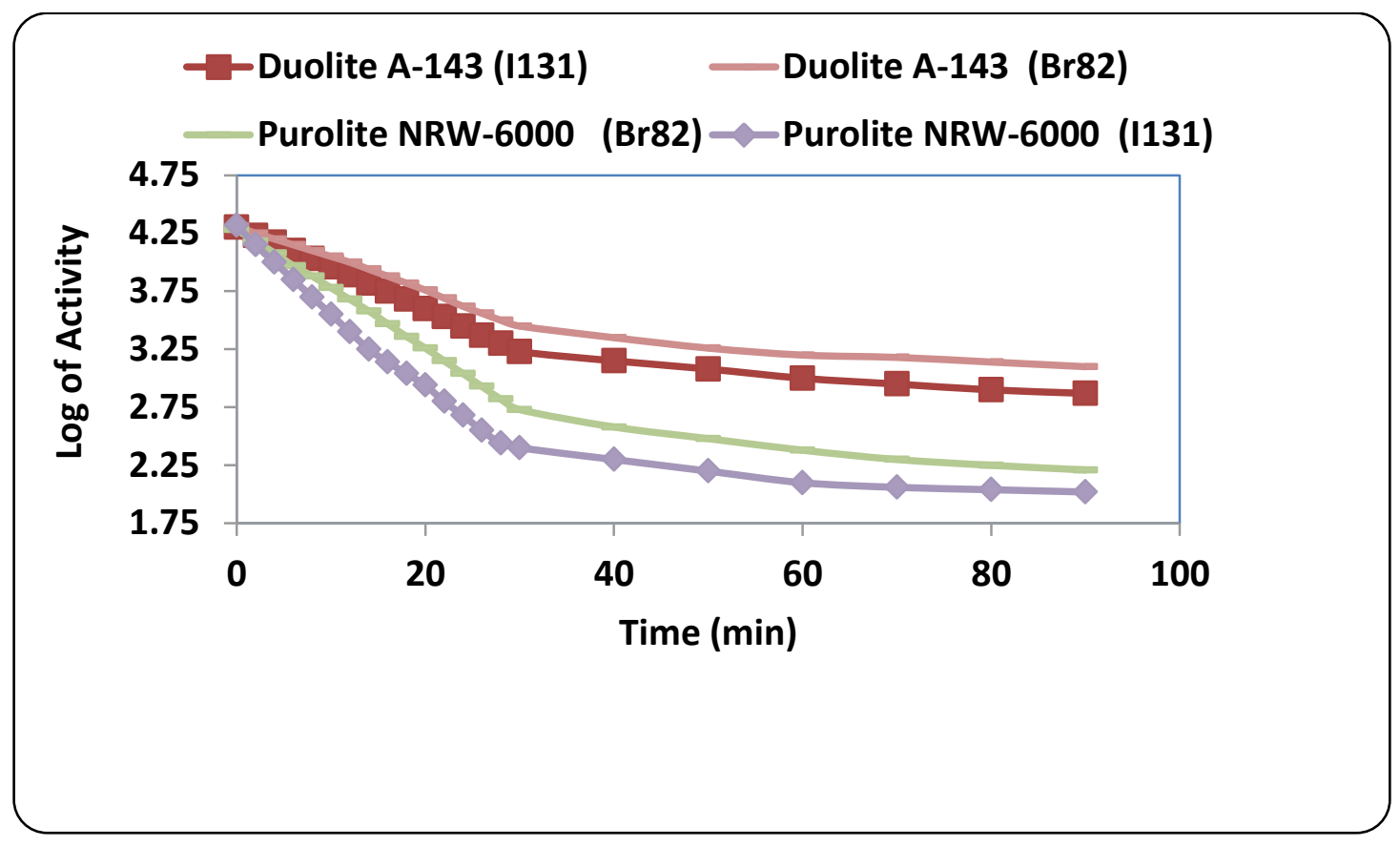

Figure 1. Kinetics of Ion-Isotopic Exchange Reactions.

Amount of ion exchange resin $=1.000 \mathrm{~g}$, Concentration of labeled exchangeable ionic solution $=0.002 \mathrm{~mol} / \mathrm{L}$, Volume of labeled ionic solution $=250 \mathrm{~mL}$, Temperature $=35.0^{\circ} \mathrm{C}$ 


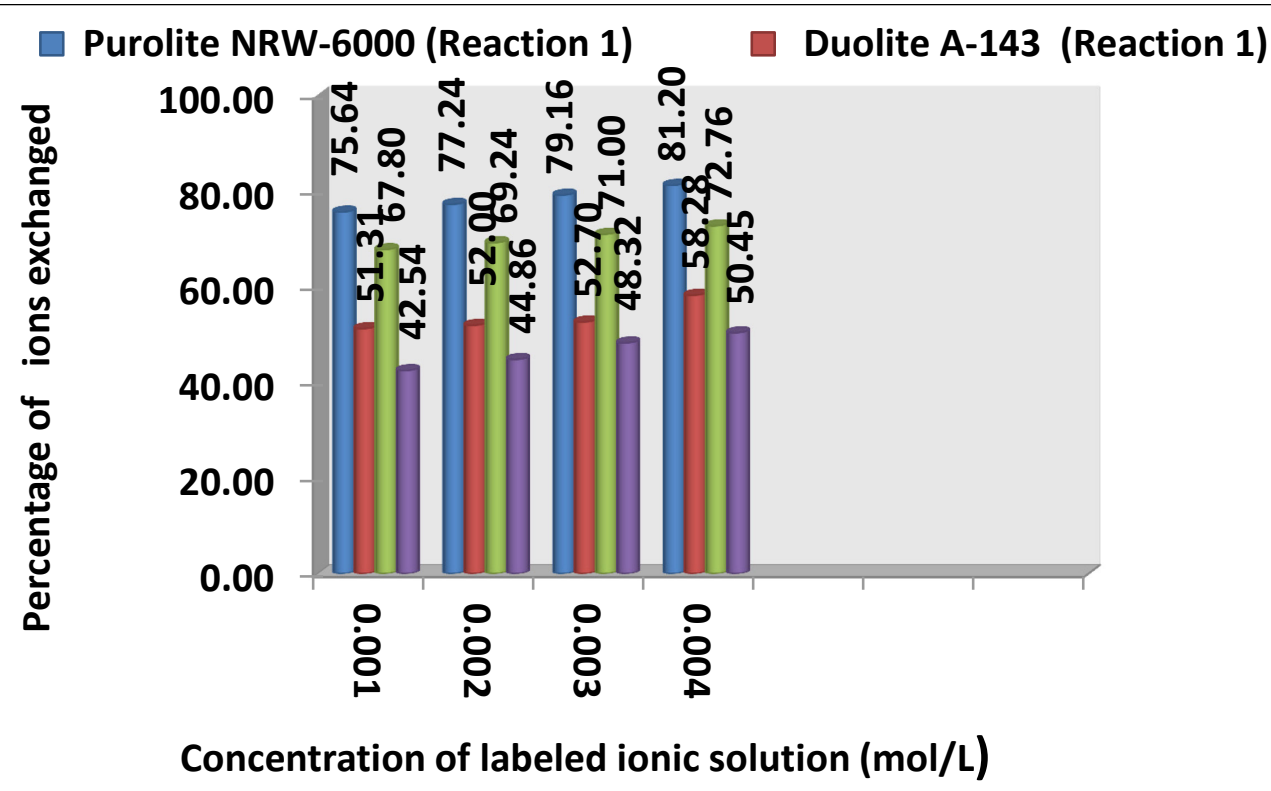

Figure 2. Variation in Percentage Ions Exchanged with Concentration of Labeled Ionic Solution. Amount of ion exchange resin $=1.000 \mathrm{~g}$, Volume of labeled ionic solution $=250 \mathrm{~mL}$, Temperature $=35.0^{\circ} \mathrm{C}$

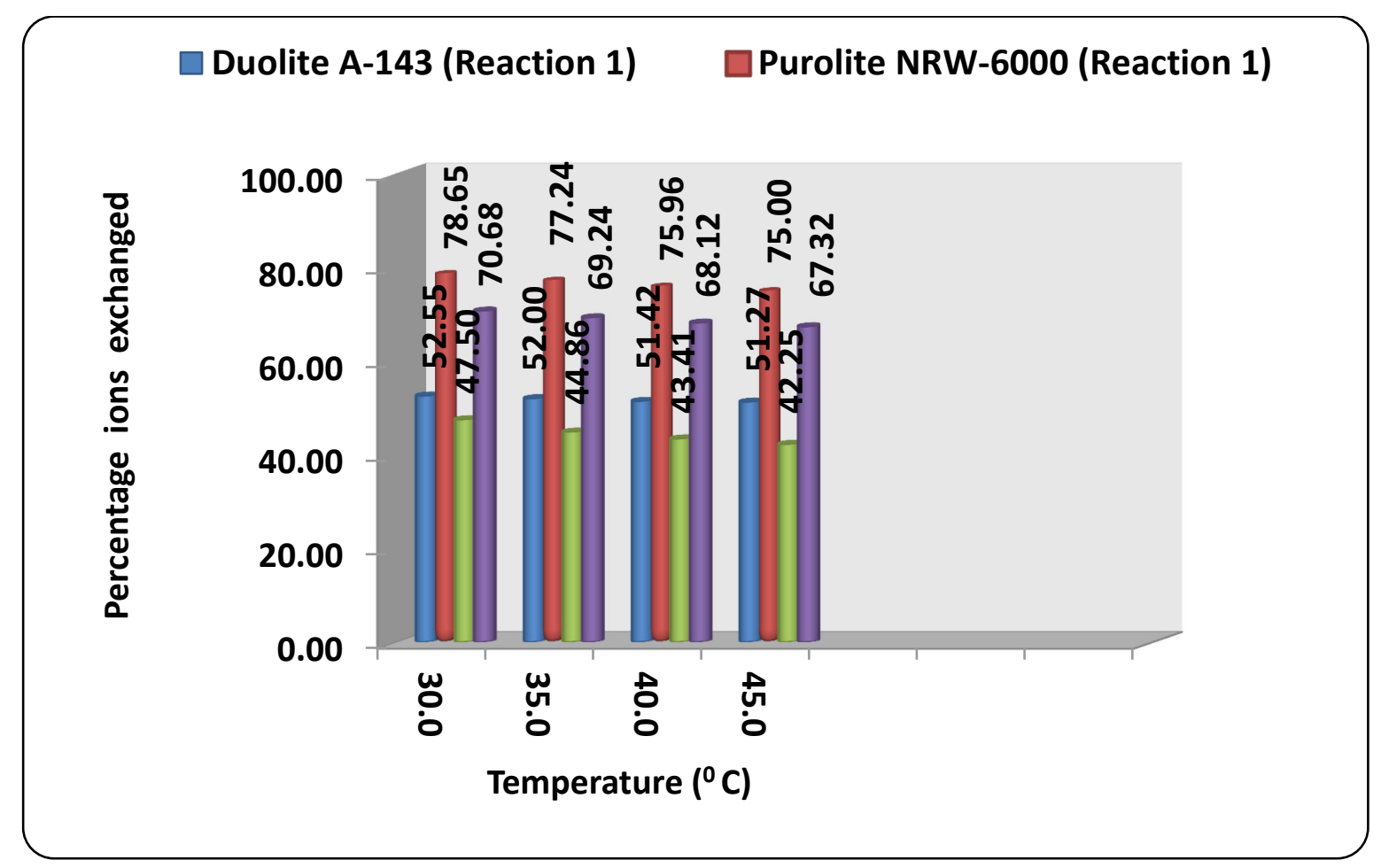

Figure 3. Variation in Percentage Ions Exchanged with Temperature of Labeled Ionic Solution Amount of ion exchange resin $=1.000 \mathrm{~g}$, Concentration of labeled exchangeable ionic solution $=0.002 \mathrm{~mol} / \mathrm{L}$, Volume of labeled ionic solution $=250 \mathrm{~mL}$, Amount of exchangeable ions in $250 \mathrm{~mL}$ labeled solution $=0.500$ mmol. 


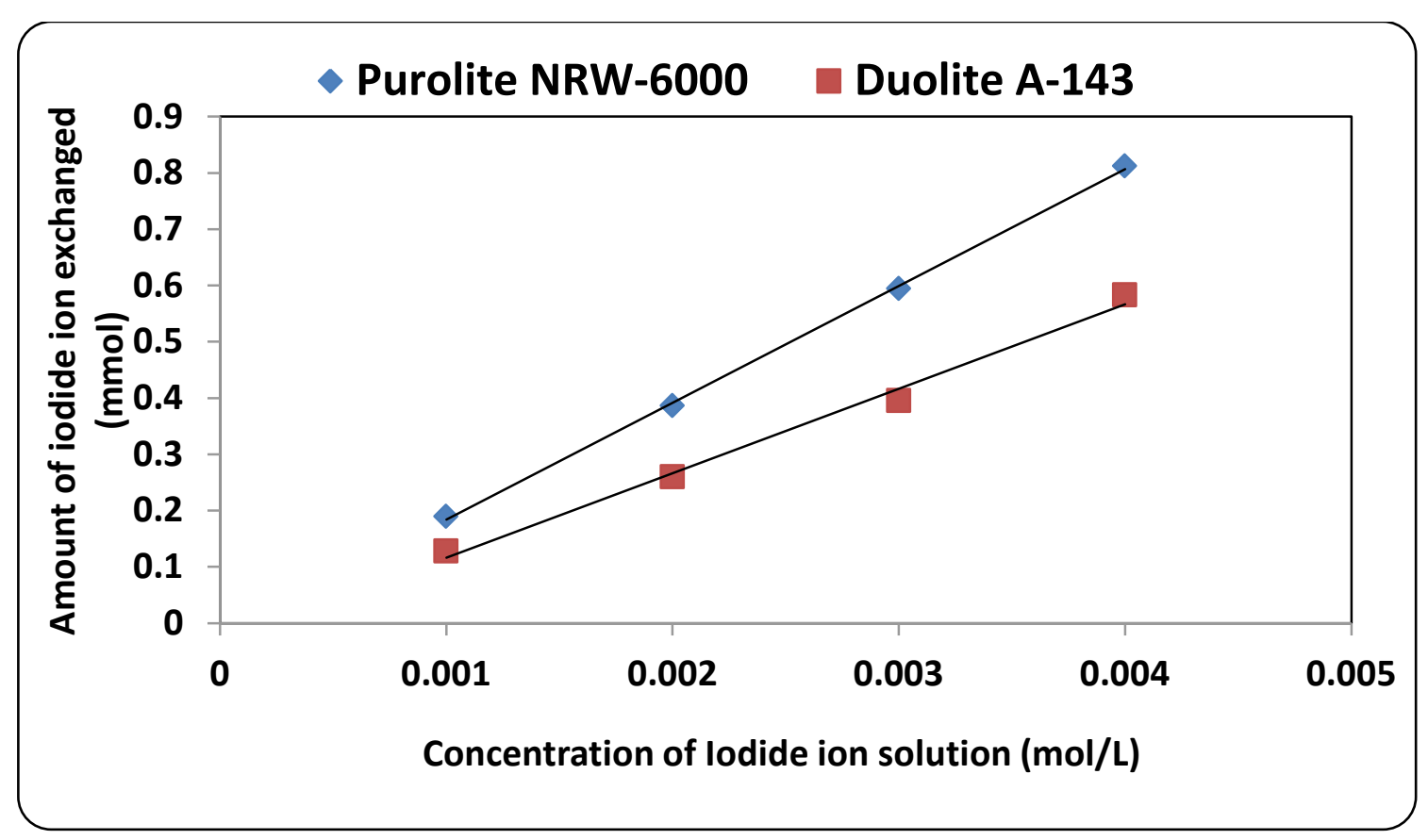

Figure 4. Correlation between concentration of iodide ion solution and amount of iodide ion exchanged. Amount of ion exchange resin $=1.000 \mathrm{~g}$, Volume of labeled ionic solution $=250 \mathrm{~mL}$, Temperature $=35.0^{\circ} \mathrm{C}$, Correlation coefficient $(\mathrm{r})$ for Purolite NRW-6000 $=0.9997$. Correlation coefficient (r) for Duolite A-143 $=0.9960$.

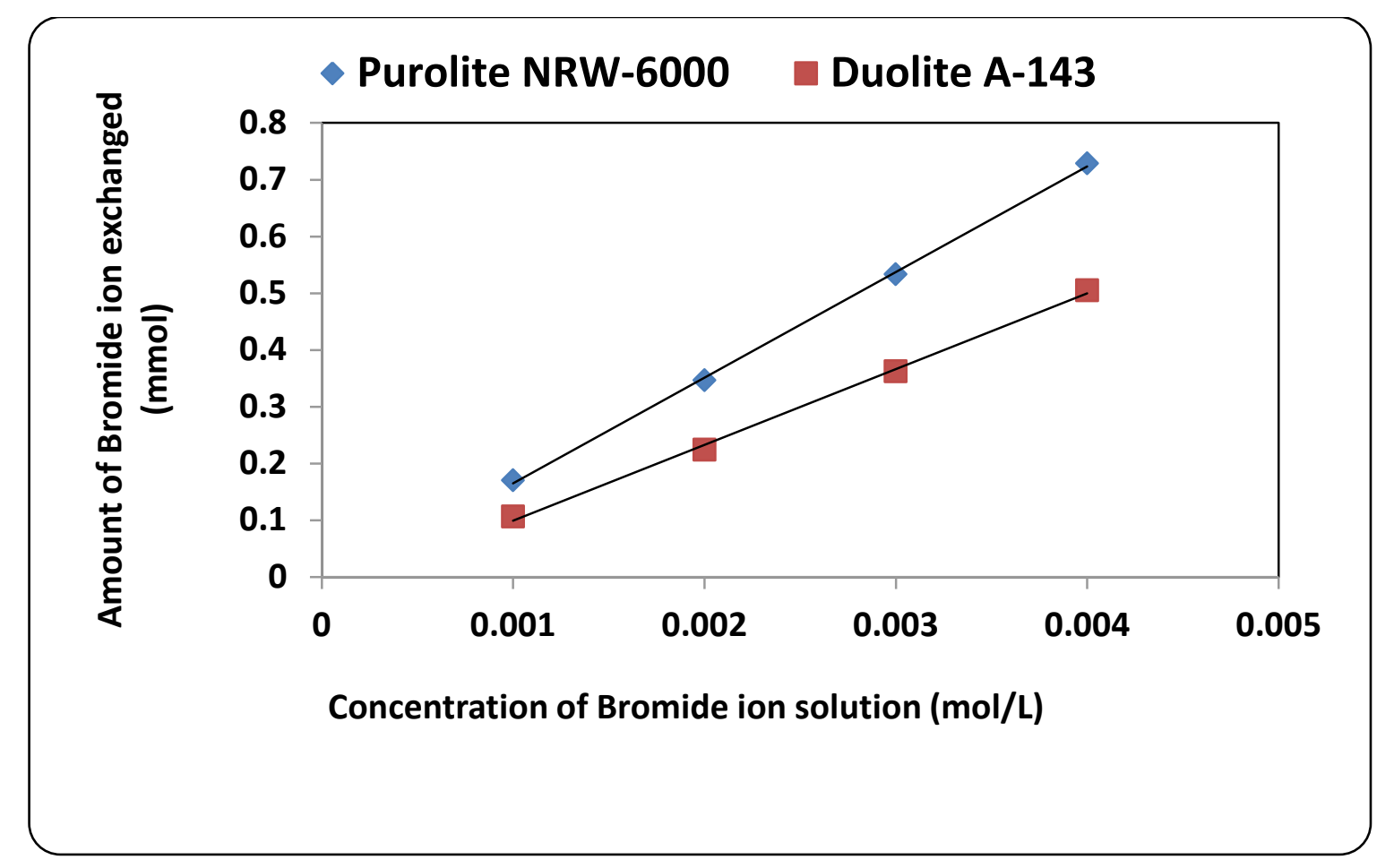

Figure 5. Correlation between concentration of bromide ion solution and amount of bromide ion exchanged. Amount of ion exchange resin $=1.000 \mathrm{~g}$, Volume of labeled ionic solution $=250 \mathrm{~mL}$, Temperature $=35.0{ }^{\circ} \mathrm{C}$. Correlation coefficient $(\mathrm{r})$ for Purolite NRW-6000 $=0.9997$. Correlation coefficient $(\mathrm{r})$ for Duolite A-143 $=0.9991$. 


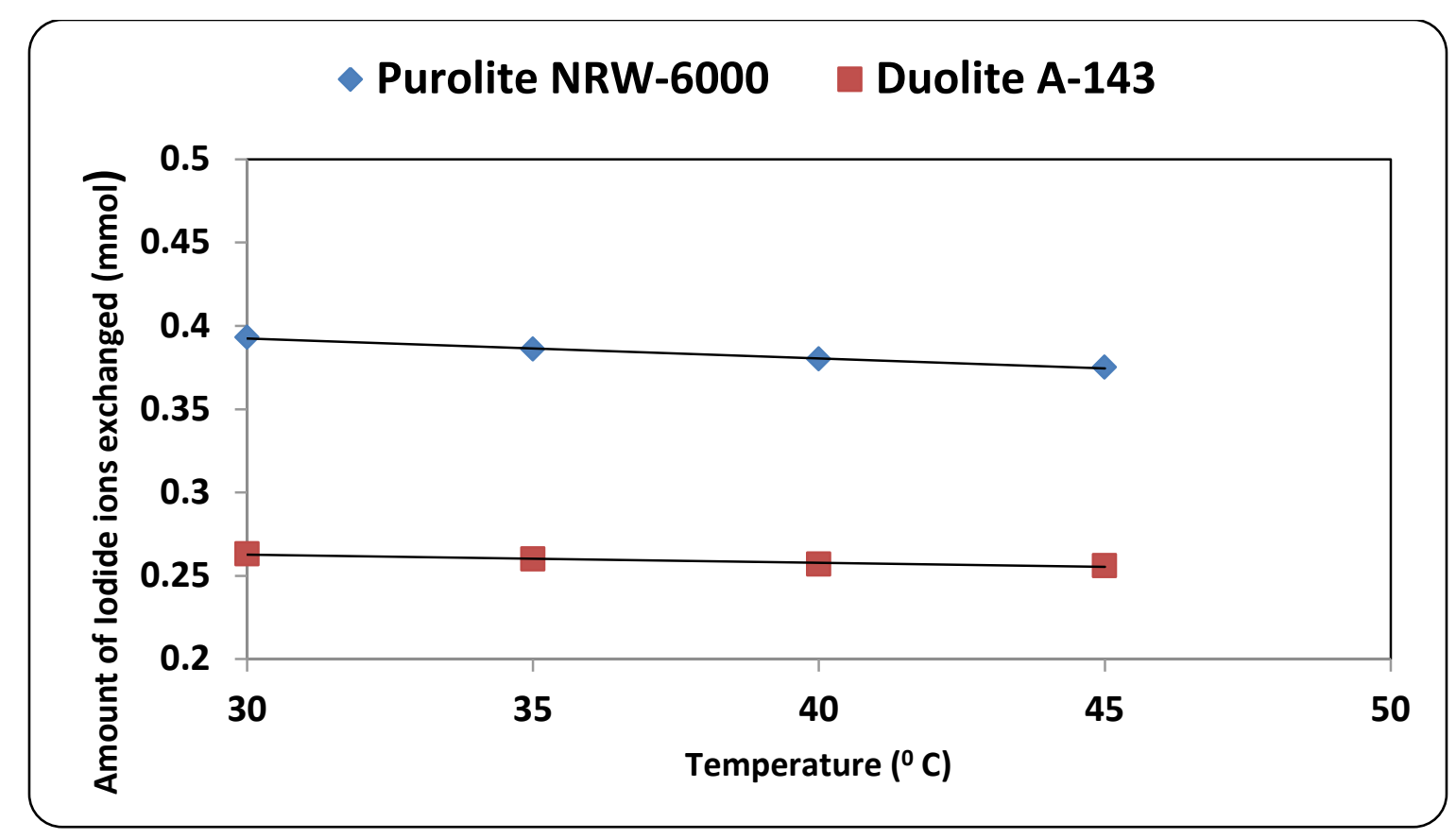

Figure 6. Correlation between Temperature of exchanging medium and amount of iodide ion exchanged. Amount of ion exchange resin $=1.000 \mathrm{~g}$, Concentration of labeled exchangeable ionic solution $=$ $0.002 \mathrm{~mol} / \mathrm{L}$, Volume of labeled ionic solution $=250 \mathrm{~mL}$, Amount of exchangeable ions in $250 \mathrm{~mL}$ labeled solution $=0.500 \mathrm{mmol}$, Correlation coefficient $(\mathrm{r})$ for Purolite NRW-6000 $=-0.9972$. Correlation coefficient $(\mathrm{r})$ for Duolite A-143 = -0.9798

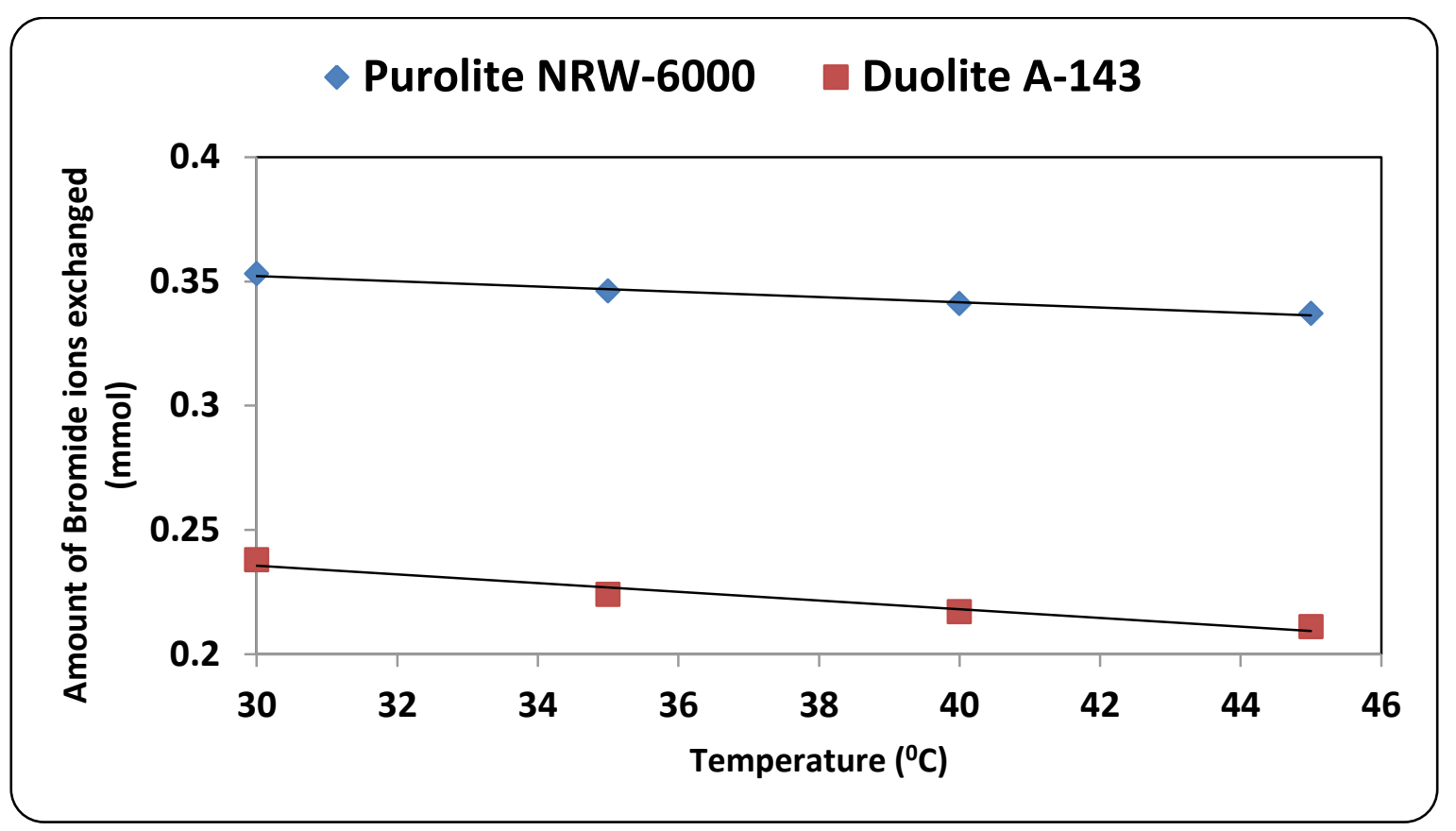

Figure 7. Correlation between Temperature of exchanging medium and amount of bromide ion exchanged. Amount of ion exchange resin $=1.000 \mathrm{~g}$, Concentration of labeled exchangeable ionic solution $=$ $0.002 \mathrm{~mol} / \mathrm{L}$, Volume of labeled ionic solution $=250 \mathrm{~mL}$, Amount of exchangeable ions in $250 \mathrm{~mL}$ labeled solution $=0.500 \mathrm{mmol}$. Correlation coefficient (r) for Purolite NRW-6000 $=-0.9919$.

Correlation coefficient $(r)$ for Duolite A-143 $=-0.9778$. 


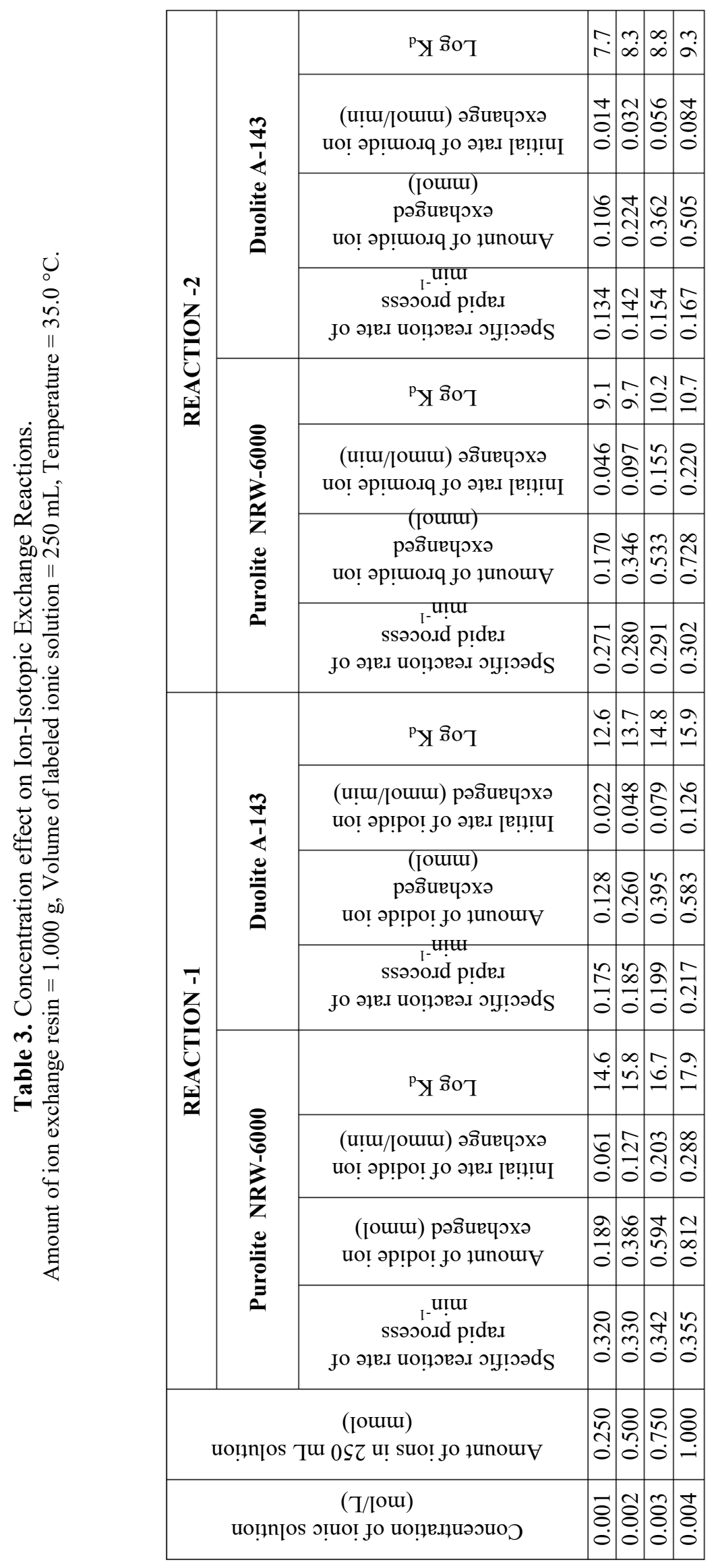




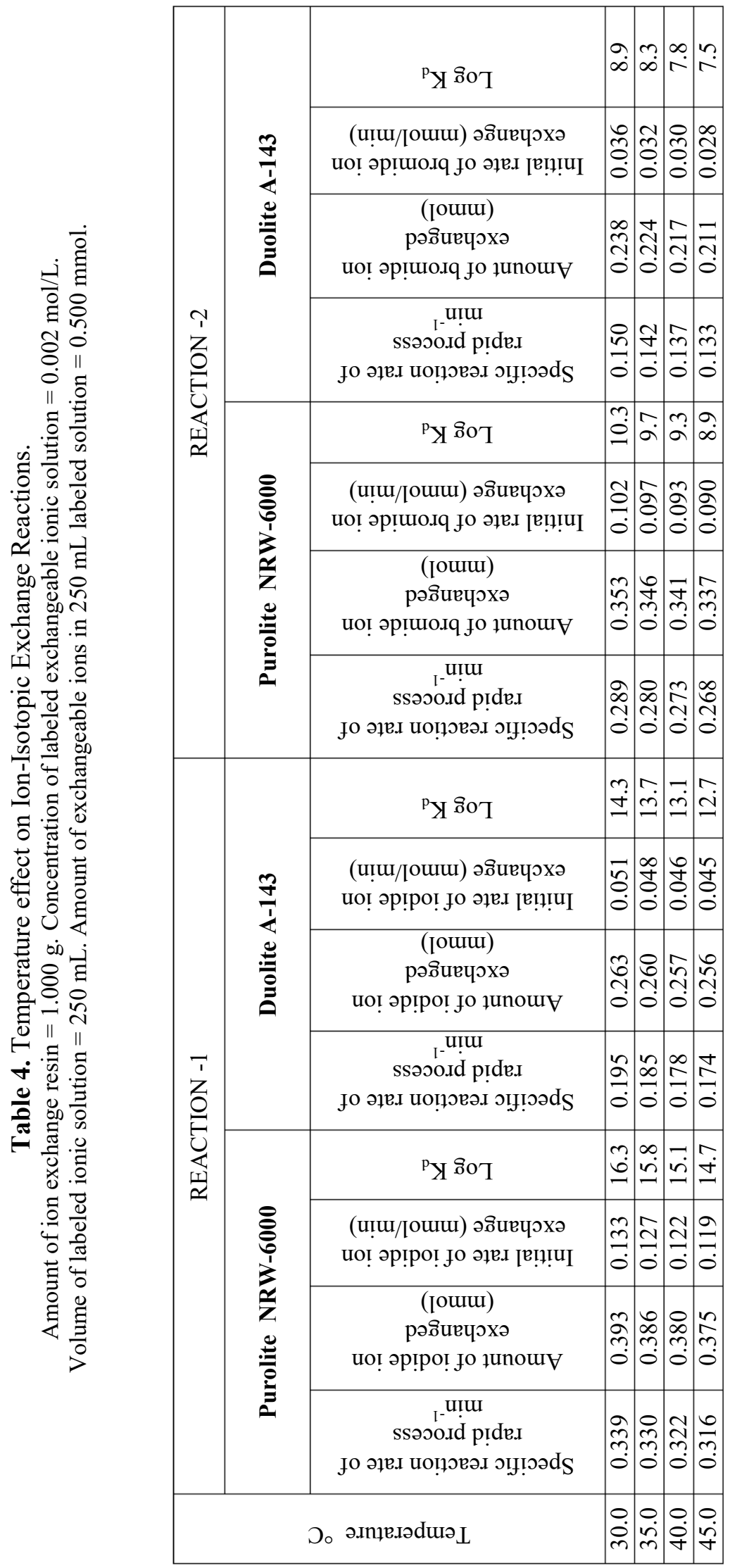




\section{RESULTS AND DISCUSSION}

\section{1. Comparative study of ion-isotopic exchange reactions}

In the present investigation it was observed that due to the rapid ion-isotopic exchange reaction taking place, the activity of solution decreases rapidly initially, then due to the slow exchange the activity of the solution decreases slowly and finally remains nearly constant. Preliminary studies show that the above exchange reactions are of first order [7-11]. Therefore logarithm of activity when plotted against time gives a composite curve in which the activity initially decreases sharply and thereafter very slowly giving nearly straight line (Figure 1), evidently rapid and slow ion-isotopic exchange reactions were occurring simultaneously [7-11]. Now the straight line was extrapolated back to zero time. The extrapolated portion represents the contribution of slow process to the total activity which now includes rapid process also. The activity due to slow process was subtracted from the total activity at various time intervals.

The difference gives the activity due to rapid process only. From the activity exchanged due to rapid process at various time intervals, the specific reaction rates $(k)$ of rapid ionisotopic exchange reaction were calculated. The amount of iodide / bromide ions exchanged (mmol) on the resin were obtained from the initial and final activity of solution and the amount of exchangeable ions in $250 \mathrm{~mL}$ of solution. From the amount of ions exchanged on the resin $(\mathrm{mmol})$ and the specific reaction rates $\left(\mathrm{min}^{-1}\right)$, the initial rate of ion exchanged (mmol/min) was calculated. Because of larger solvated size of bromide ions as compared to that of iodide ions, it was observed that the exchange of bromide ions occurs at the slower rate than that of iodide ions. Hence under identical experimental conditions, the values of specific reaction rate $\left(\mathrm{min}^{-1}\right)$, amount of ion exchanged $(\mathrm{mmol})$ and initial rate of ion exchange ( $\mathrm{mmol} / \mathrm{min}$ ) are calculated to be lower for bromide ion-isotopic exchange reaction than that for iodide ion-isotopic exchange reaction as summarized in Tables 3 and 4. For both bromide and iodide ion-isotopic exchange reactions, under identical experimental conditions, the values of specific reaction rate increases with increase in the concentration of iodide and bromide ions in solution from $0.001 \mathrm{~mol} / \mathrm{L}$ to $0.004 \mathrm{~mol} / \mathrm{L}$ (Table 3 ).

However, with rise in temperature from $30.0^{\circ} \mathrm{C}$ to $45.0{ }^{\circ} \mathrm{C}$, the specific reaction rate was observed to decrease (Table 4). Thus in case of Purolite NRW-6000 at $35.0^{\circ} \mathrm{C}$ when the concentration of iodide and bromide ions in solution increases from $0.001 \mathrm{~mol} / \mathrm{L}$ to 0.004 $\mathrm{mol} / \mathrm{L}$, the specific reaction rate values for iodide ion-isotopic exchange increases from 0.320 to $0.355 \mathrm{~min}^{-1}$, while for bromide ion-isotopic exchange the values increases from 0.271 to $0.302 \mathrm{~min}^{-1}$. Similarly in case of Duolite A-143, under identical experimental conditions, the values for iodide ion-isotopic exchange increases from 0.175 to $0.217 \mathrm{~min}^{-1}$, while for bromide ion-isotopic exchange the values increases from 0.134 to $0.167 \mathrm{~min}^{-1}$. However when the concentration of iodide and bromide ions in solution is kept constant at $0.002 \mathrm{~mol} / \mathrm{L}$ and temperature is raised from $30.0{ }^{\circ} \mathrm{C}$ to $45.0{ }^{\circ} \mathrm{C}$, in case of Purolite NRW-6000 the specific reaction rate values for iodide ion-isotopic exchange decreases from 0.339 to $0.316 \mathrm{~min}^{-1}$, while for bromide ion-isotopic exchange the values decreases from 0.289 to $0.268 \mathrm{~min}^{-1}$.

Similarly in case of Duolite A-143, under identical experimental conditions, the specific reaction rate values for iodide ion-isotopic exchange decreases from 0.195 to $0.174 \mathrm{~min}^{-1}$, while for bromide ion-isotopic exchange the values decreases from 0.150 to $0.133 \mathrm{~min}^{-1}$. From the results, it appears that iodide ions exchange at the faster rate as compared to that of bromide ions which was related to the extent of solvation (Tables 3 and 4). From the knowledge of $A_{i}, A_{f}$, volume of the exchangeable ionic solution $(V)$ and mass of ion exchange resin $(m)$, the $K_{d}$ value was calculated by the equation:

$$
K_{d}=\left[\left(A_{i}-A_{f}\right) / A_{f}\right] \times V / m
$$


Previous studies $[12,13]$ on halide ion distribution coefficient on strong and weak basic anion exchange resins indicate that the selectivity coefficient between halide ions increased at higher electrolyte concentrations. Adachi et al. [14] observed that the swelling pressure of the resin decreased at higher solute concentrations resulting in larger $\mathrm{K}_{d}$ values. The temperature dependence of $K_{d}$ values on cation exchange resin was studied by Shuji et al. [15]; were they observed that the values of $K_{d}$ increased with fall in temperature.

The present experimental results also indicates that the $\mathrm{K}_{\mathrm{d}}$ values for bromide and iodide ions increases with increase in ionic concentration of the external solution, however with rise in temperature the $K_{d}$ values were found to decrease. Thus in case of Purolite NRW6000 at $35.0^{\circ} \mathrm{C}$ when the concentration of iodide and bromide ions in solution increases from $0.001 \mathrm{~mol} / \mathrm{L}$ to $0.004 \mathrm{~mol} / \mathrm{L}$, the $\log \mathrm{K}_{\mathrm{d}}$ values for iodide ions increases from 14.6 to 17.9 , while for bromide ions the values increases from 9.1 to 10.7. Similarly in case of Duolite A143, under identical experimental conditions, the $\log \mathrm{K}_{\mathrm{d}}$ values for iodide ions increases from 12.6 to 15.9 , while for bromide ions the values increases from 7.7 to 9.3. However when the concentration of iodide and bromide ions in solution is kept constant at $0.002 \mathrm{~mol} / \mathrm{L}$ and temperature is raised from $30.0{ }^{\circ} \mathrm{C}$ to $45.0{ }^{\circ} \mathrm{C}$, in case of Purolite NRW-6000 the $\log \mathrm{K}_{\mathrm{d}}$ values for iodide ions decreases from 16.3 to 14.7 , while for bromide ions the values decreases from 10.3 to 8.9. Similarly in case of Duolite A-143, under identical experimental conditions, the $\log \mathrm{K}_{\mathrm{d}}$ values for iodide ions decreases from 14.3 to 12.7 , while for bromide ions the values decreases from 8.9 to 7.5 . It was also observed that the $\mathrm{K}_{\mathrm{d}}$ values for iodide ion-isotopic exchange reaction were calculated to be higher than that for bromide ion-isotopic exchange reaction (Tables 3 and 4).

\section{2. Comparative study of anion exchange resins}

From the Table 3 and 4, it is observed that for iodide ion-isotopic exchange reaction by using Purolite NRW-6000 resin, the values of specific reaction rate $\left(\mathrm{min}^{-1}\right)$, amount of iodide ion exchanged ( $\mathrm{mmol}$ ), initial rate of iodide ion exchange $(\mathrm{mmol} / \mathrm{min})$ and $\log \mathrm{K}_{\mathrm{d}}$ were 0.330 , $0.386,0.127$ and 15.8 respectively, which was higher than $0.185,0.260,0.048$ and 13.7 respectively as that obtained by using Duolite A-143 resins under identical experimental conditions of $35.0^{\circ} \mathrm{C}, 1.000 \mathrm{~g}$ of ion exchange resins and $0.002 \mathrm{~mol} / \mathrm{L}$ labeled iodide ion solution. The identical trend was observed for the two resins during bromide ion-isotopic exchange reaction.

From Table 3, it is observed that at a constant temperature of $35.0{ }^{\circ} \mathrm{C}$, as the concentration of labeled iodide ion solution increases from $0.001 \mathrm{~mol} / \mathrm{L}$ to $0.004 \mathrm{~mol} / \mathrm{L}$, the percentage of iodide ions exchanged increases from $75.64 \%$ to $81.20 \%$ using Purolite NRW6000 resins and from $51.31 \%$ to $58.28 \%$ using Duolite A-143 resins. Similarly in case of bromide ion-isotopic exchange reactions under identical experimental conditions, the percentage of bromide ions exchanged increases from $67.80 \%$ to $72.76 \%$ using Purolite NRW-6000 resin and from $42.54 \%$ to $50.45 \%$ using Duolite A-143 resin. The effect of ionic concentration on percentage of ions exchanged is graphically represented in Figure 2.

From Table 4, it is observed that for $0.002 \mathrm{~mol} / \mathrm{L}$ labeled iodide ion solution, as the temperature increases from $30.0{ }^{\circ} \mathrm{C}$ to $45.0{ }^{\circ} \mathrm{C}$, the percentage of iodide ions exchanged decreases from $78.65 \%$ to $75.00 \%$ using Purolite NRW-6000 resins and from $52.55 \%$ to $51.27 \%$ using Duolite A-143 resins. Similarly under identical experimental conditions, in case of bromide ion-isotopic exchange reactions, the percentage of bromide ions exchanged decreases from $70.68 \%$ to $67.32 \%$ using Purolite NRW-6000 resin and from $47.50 \%$ to $42.25 \%$ using Duolite A-143 resin. The effect of temperature on percentage of ions exchanged is graphically represented in Figure 3. 
The overall results indicate that under identical experimental conditions, as compared to Duolite A-143 resins, Purolite NRW-6000 resins shows higher percentage of ions exchanged. Thus Purolite NRW-6000 resins show superior performance over Duolite A-143 resins under identical operational parameters.

\section{3. Statistical Correlations}

The results of present investigation show a strong positive linear correlation between amount of ions exchanged and concentration of ionic solution (Figures 4, 5). In case of iodide ion-isotopic exchange reaction, the values of correlation coefficient $(r)$ were calculated as 0.9997 and 0.9960 for both Purolite NRW-6000 and Duolite A-143 resins respectively, while for bromide ion-isotopic exchange reaction, the values of $r$ was calculated as 0.9997 and 0.9991 respectively for the two resins.

There also exist a strong negative correlation between amount of ions exchanged and temperature of exchanging medium (Figures 6, 7). In case of iodide ion-isotopic exchange reactions the values of $r$ calculated for Purolite NRW-6000 and Duolite A-143 resins were 0.9972 and -0.9798 respectively. Similarly in case of bromide ion-isotopic exchange reactions the $r$ values calculated were -0.9919 and -0.9778 respectively for both the resins.

\section{CONCLUSION}

The experimental work carried out in the present investigation will help to standardize the operational process parameters so as to improve the performance of selected ion exchange resins. The radioactive tracer technique used here can also be applied for characterization of different nuclear as well as non-nuclear grade ion exchange resins.

\section{Acknowledgement}

The author is thankful to Professor Dr. R. S. Lokhande (Retired) for his valuable help and support by providing the required facilities so as to carry out the experimental work in Radiochemistry Laboratory, Department of Chemistry, University of Mumbai, Vidyanagari, Mumbai-58.

\section{References}

[1] Samanta S. K., Ramaswamy M., Misra B. M., Sep. Sci. Technol. 27 (1992) 255-267.

[2] Samanta S. K., Theyyunni T. K., Misra B. M., J. Nucl. Sci. Technol. 32 (1995) 425-429.

[3] Application of Ion Exchange Processes For the Treatment of Radioactive Waste and Management of Spent Ion Exchangers, Technical Reports Series No. 408, International Atomic Energy Agency, Vienna, 2002.

[4] Kumaresan R., Sabharwal K. N., Srinivasan T. G., Vasudeva Rao P. R., Dhekane G., Solvent Extraction and Ion Exchange 24(4) (2006) 589-602.

[5] Deborah L. S., Nazila K., Douglas B. K., James A. D., Geochemical Transactions 14 (2013) 1. 
[6] Sood D. D., Reddy A. V. R., Ramamoorthy N., Indian Association of Nuclear Chemists and Allied Scientists, January (2004) 289-297.

[7] Singare P. U., Lokhande R. S., Ionics 18(4) (2012) 351-357.

[8] Lokhande R. S., Singare P. U., Radiochim. Acta 95(03) (2007) 173-176.

[9] Lokhande R. S., Singare P. U., Patil V.V., Radiochemistry 50(06) (2008) 638-641.

[10] Lokhande R. S., Singare P. U., J. Porous Mater 15(03) (2008) 253-258.

[11] Lokhande R. S., Singare P. U., Dole M. H., J. Nuclear and Radiochemical Sciences 7(02) (2006) 29-32.

[12] Heumann K. G., Baier K., Chromatographia 15(11) (1982) 701-703.

[13] Singare P. U., Lokhande R. S., Patil V. V., Prabhavalkar T. S., Tiwari S. R. D., European J. Chemistry 1(1) (2010) 47-49.

[14] Adachi S., Mizuno T., Matsuno R., J. Chromatogr. A 708 (1995) 177-183.

[15] Shuji A., Takcshi M., Ryuichi M., Biosci. Biotechnol. Biochem. 60(2) (1996) 338-340. 